\title{
Subcutaneous ICD for more and transvenous ICD for few?!
}

\author{
Amr Abdin ${ }^{1}(1) \cdot$ Suleman Aktaa ${ }^{2,3,4}$ \\ Received: 6 October 2021 / Accepted: 7 February 2022 / Published online: 18 February 2022 \\ (c) The Author(s) 2022
}

\begin{abstract}
Implantable cardioverter defibrillators (ICDs) have been shown to reduce the risk of sudden cardiac death in primary or secondary prevention with thousands of ICDs implanted every year worldwide. Whilst ICD are more commonly implanted transvenously (TV), this approach carries high risk of peri- and post-procedural complications. Subcutaneous ICD (S-ICD) have been introduced to overcome the intravascular complications of TV system by placing all metalware outside the chest cavity for those with an indication for a defibrillator and no pacing requirements. In conclusion, a review of the current guidelines recommendations regarding S-ICD may be needed considering the emerging evidence which shows high efficacy and safety with contemporary devices and programming algorithms. A stronger recommendation may be developed for selective patients who have an indication for single-chamber ICD in the absence of negative screening, recurrent monomorphic ventricular tachycardia, cardiac resynchronization therapy, or pacemaker indication. These criteria encapsulate a large proportion (around 70\%!) of all ICD eligible patients.
\end{abstract}

Keywords Sudden cardiac death · Implantable cardioverter defibrillator $\cdot$ Subcutaneous ICD

Despite the advances in diagnostics and therapies of cardiovascular disease, sudden cardiac death (SCD) remains a major challenge accounting for approximately $0.1-0.2 \%$ deaths per year [1]. Implantable cardioverter defibrillators (ICDs) have been shown to reduce the risk of SCD in primary or secondary prevention $[1,2]$ with thousands of ICDs implanted every year worldwide [3, 4]. Whilst ICD are more commonly implanted transvenously (TV), this approach carries high risk of peri- and post-procedural complications [3, 5]. For instance, pneumothorax as well as cardiac and vascular damage are recognized complications that are associated with TV-ICDs at the time of implantation (up to 3.5\%)

Amr Abdin

amr.abdin@uks.eu

1 Klinik Für Innere Medizin III-Kardiologie, Angiologie Und Internistische Intensivmedizin, Universitätsklinikum Des Saarlandes, Kirrberger Strasse 100, 66421 Homburg, Germany

2 Leeds Institute for Data Analytics, University of Leeds, Leeds, UK

3 Leeds Institute of Cardiovascular and Metabolic Medicine, University of Leeds, Leeds, UK

4 Department of Cardiology, Leeds Teaching Hospitals NHS Trust, Leeds, UK
[6]. After having implanted the TV-ICD system without any acute complications, the long-term complications are faced, which are mainly lead related problems and might be seen in around 25\% of TV-ICD over the first decade following implantation $[3,5,7]$. Furthermore, TV-ICD is prone to systemic infections which may result in the need for device extraction and the subsequent morbidity and mortality [8]. For illustration, mortality following TV-ICD system removal due to pocket and endovascular infection can reach $31 \%$ at 1 year [8].

Subcutaneous ICD (S-ICD) have been introduced to overcome the intravascular complications of TV systems by placing all metalware outside the thorax cavity for those with an indication for a defibrillator and no pacing requirements [3]. Pooled data from long-term registries showed the devicerelated complications after S-ICD implantation occurred in $11.1 \%$ of patients at 3 years [9]. Moreover, lead failures rate was rarely reported [3, 9]. However, On December 2020, a medical advisory letter regarding EMBLEM S-ICD electrode model 3501 (Boston Scientific, Marlborough, MA) was released by Boston Scientific Corporation [10]. According to their data, there have been 27 cases of electrode body fractures, resulting in life-threatening events of 1 in 25,000 at 10 years. The overall lead failure rate is still lower than what has been reported with TV-ICD leads $[5,11,12]$. 
Notwithstanding that international guideline, including these of the European Society of Cardiology (ESC) and the American College of Cardiology (ACC) / American Heart Association (AHA) recommend S-ICD only as an alternative strategy to TV-ICD for eligible patients [1, 2], their recommendations were based mainly on early S-ICD studies which were observational prospective analyses [3]. These studies could prove the reliability of S-ICD in detecting and terminating ventricular arrhythmias [3]. However, more recently, the PRAETORIAN (Prospective, Randomized comparison of subcutaneous and transvenous Implantable cardioverter defibrillator therapy) [13] and the Understanding Outcomes With the S-ICD in Primary Prevention Patients With Low Ejection Fraction (UNTOUCHED) trials [14] were published. The PRAETORIAN trial was a randomized trial which included 849 patients with an indication for ICD therapy to either TV- or S-ICD. After a median follow-up of 48 months, the primary endpoint of inappropriate shocks or device-related complications occurred in $15.7 \%$ in TV-ICD and $15.1 \%$ in S-ICD recipients ( $P=0.01$ for noninferiority) [13]. Interestingly, during 4 years of follow-up, only $0.9 \%$ of patients required TV-ICD for pacing and $0.2 \%$ for ATP.

The UNTOUCHED study enrolled 1111 patients with a primary prevention ICD indication, and no indication for pacemaker [14]. The inappropriate shock-free rate at 18 months (i.e., the study's primary endpoint) was $95.9 \%$ $(P<0.001$ vs the prespecified performance goal of $91.6 \%)$. During 18 months of follow-up, only $0.2 \%$ of patients required TV-ICD for ATP.

Hence, with increasing physician experience in implantation and programming as well as improvements in the detection, filter, and discrimination algorithms, the rate of inappropriate shocks has decreased over the years. Indeed, the yearly rate of inappropriate shocks observed in UNTOUCHED patients was $3.1 \%$, which was further reduced to $2.4 \%$ with the Gen 3 devices. This rate was with the range of that observed in current TV-ICDs trials $[12,14]$.

In view of this:

\section{Novel perspectives}

Why not S-ICD as a first line therapy for all ICD patients?!

According to the Italian S-ICD survey around $88 \%$ of all ICD indicated patients were eligible to receive an S-ICD [11]. However, S-ICD was only implanted in $12 \%$ of patients with no cardiac synchronization therapy (CRT) indication. Although the most common reasons for preferring a TVICD over an S-ICD were the need for permanent pacing or ATP therapy, at the time of ICD implantation, only $7-10 \%$ of patients fulfilled conditions for Class I recommendation for permanent pacing [15]. An additional 4\% of patients presented with a history of unstable monomorphic ventricular tachycardia that might have been treatable with ATP. Furthermore, even in countries with high ICDs implantation rates such as Germany, only $6 \%$ of the 23,000 patients who had ICD implantation in 2018 received S-ICD [4].

The modular cardiac rhythm management (mCRM) system, involving of a communicating ATP-enabled EMPOWERTM LCP and EMBLEMTM platform S-ICD system, which enables the coordination of leadless pacing and defibrillator therapy delivery [16]. The modular ATP is a current randomized controlled trial assessing the safety and efficacy of an individualized approach to ICD therapy that providing a solution for patients who may develop a need for pacing or ATP in the future [16].

In conclusion, a review of the current guidelines recommendations regarding S-ICD may be needed considering the emerging evidence which shows high efficacy and safety with contemporary devices and programming algorithms. A stronger recommendation may be developed for selective patients who have an indication for single-chamber ICD in the absence of negative screening, recurrent monomorphic ventricular tachycardia, cardiac resynchronization therapy, or pacemaker indication. According to the existing evidence, these criteria encapsulate a large proportion (around 60\%!) of all ICD eligible patients (Fig. 1) [15-19].

Other criteria which may favor S-ICD include, young patients with a long-life expectancy and patients at risk of infection with diseases such as diabetes mellitus or renal insufficiency requiring dialysis or venous access issues should be also provided with an S-ICD as far as possible in order to avoid complications and to preserves the venous system for other purposes [11, 14].

Nonetheless, S-ICD has additional important limitations which are the large pulse generator, with anticipated life battery shorter than TV-ICD and the relatively high costs [14]. Moreover, the current recommendation for S-ICD implantation is to perform defibrillation testing (DFT) to determine the ability of the device at terminating ventricular fibrillation [12]. In a recent published propensity-matched study, DFT was not associated with significant differences in ineffective shocks and cardiovascular mortality. The PRAETORIANDFT is a current randomized controlled trial assessing DFT in the S-ICD which should elucidate the need for DFT in the S-ICD [20].

Based on the above, appropriate patient selection with risk-benefit assessment alongside contemporary device programming is an essential parameter to the selection and success of S-ICDs. 


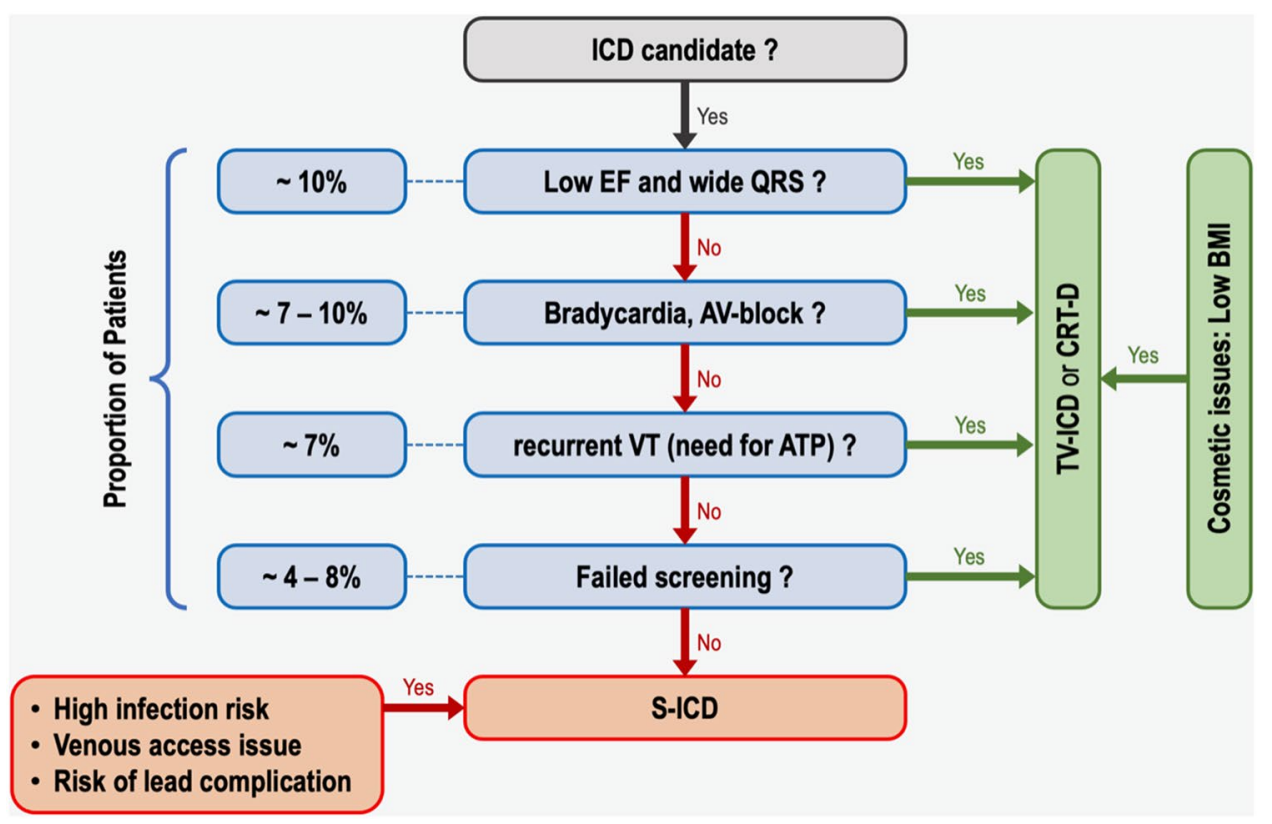

Fig. 1 Algorithm to define suitable patients for S-ICD. This figure shows an algorithm to define suitable patients for S-ICD. Patients with low left ventricular ejection fraction (EF) and wide QRS complex (accounting 10\% of all ICD population at implant) should receive a CRT-D. Patients with an indication for pacemaker should receive a TV-ICD or CRT-D (accounting $7-10 \%$ of all ICD popula-

Funding Open Access funding enabled and organized by Projekt DEAL. None.

\section{Declarations}

Conflict of interest Nothing to declare.

Open Access This article is licensed under a Creative Commons Attribution 4.0 International License, which permits use, sharing, adaptation, distribution and reproduction in any medium or format, as long as you give appropriate credit to the original author(s) and the source, provide a link to the Creative Commons licence, and indicate if changes were made. The images or other third party material in this article are included in the article's Creative Commons licence, unless indicated otherwise in a credit line to the material. If material is not included in the article's Creative Commons licence and your intended use is not permitted by statutory regulation or exceeds the permitted use, you will need to obtain permission directly from the copyright holder. To view a copy of this licence, visit http://creativecommons.org/licenses/by/4.0/.

\section{References}

1. Al-Khatib SM, Stevenson WG, Ackerman MJ, Bryant WJ, Callans DJ, Curtis AB et al (2018) 2017 AHA/ACC/HRS guideline for management of patients with ventricular arrhythmias and the prevention of sudden cardiac death: executive summary: a report of the American College of Cardiology/American Heart Association Task Force on clinical practice guidelines and the Heart Rhythm Society. Circulation 138:e210-e271 tion at implant). Patients with recurrent monomorphic ventricular tachycardia (VT) should also receive a TV-ICD (7\% of all ICD population at implant). After excluding the above-mentioned group of patients a screening for S-ICD should be performed (can be failed in 4-10\%), Data taken from [15-19]

2. Priori SG, Blomstrom-Lundqvist C, Mazzanti A, Blom N, Borggrefe M, Camm J, et al. 2015 ESC guidelines for the management of patients with ventricular arrhythmias and the prevention of sudden cardiac death: the task force for the management of patients with ventricular arrhythmias and the prevention of sudden cardiac death of the European Society of Cardiology (ESC). Endorsed by: association for European Paediatric and Congenital Cardiology (AEPC). Eur Heart J. 2015; 36:2793-2867.

3. Steffel J (2020) The subcutaneous ICD for prevention of sudden cardiac death: Current evidence and future directions. Pacing Clin Electrophysiol 43:1421-1427

4. Markewitz A., Bundesfachgruppe Herzschrittmacher und Defibrillatoren. Jahresbericht 2018 des Deutschen Herzschrittmacher- und Defibrillator-Registers-Teil 2: Implantierbare Kardioverter-Defibrillatoren (ICD). Herzschr Elektrophys.2021; 32: 75-88

5. Nordkamp LRAO, Postema PG, Knops RE, Dijk NA, Limpens J, Wilde AAM et al (2016) Implantable cardioverter-defibrillator harm in young patients with inherited arrhythmia syndromes: a systematic review and meta-analysis of inappropriate shocks and complications. Heart Rhythm 13:443-454

6. Burri H, Starck C, Auricchio A, Biffi M, Burri M, D’Avila A et al (2021) EHRA expert consensus statement and practical guide on optimal implantation technique for conventional pacemakers and implantable cardioverter-defibrillators: endorsed by the Heart Rhythm Society (HRS), the Asia Pacific Heart Rhythm Society (APHRS), and the Latin-American Heart Rhythm Society (LAHRS). Europace 23(7):983-1008

7. Koneru JN, Jones PW, Hammill EF, Wold N, Ellenbogen KA. Risk Factors and Temporal Trends of Complications Associated With Transvenous Implantable Cardiac Defibrillator Leads. J Am Heart Assoc. 2018; 7:e007691. 
8. Tarakji KG, Ellis CR, Defaye P, Kennergren C (2016) Cardiac Implantable Electronic Device Infection in Patients at Risk. Arrhythm Electrophysiol Rev 5:65-71

9. Burke MC, Gold MR, Knight BP, Barr CS, Theuns DA, Boersma LVA et al (2015) Safety and efficacy of the totally subcutaneous implantable defibrillator: 2-year results from a pooled analysis of the IDE study and EFFORTLESS registry. $\mathrm{J}$ Am Coll Cardiol 65:1605-1615

10. Boston Scientific. Important medical device advisory. Boston Scientific, December 2020. https://www.bostonscientific.com/ content/dam/bostonscientific/quality/dlt/reg-code-228/2020D ec_BSC_EmblemElectrode3501_PhysLtr_Final.pdf. Accessed 22 Mar 2021.

11. Kleemann T, Becker T, Doenges K et al (2007) Annual rate of transvenous defibrillation lead defects in implantable cardioverter-defibrillators over a period of $>10$ years. Circulation 115:2474-2480

12. Karimianpour A, John L, Gold MR (2021) The subcutaneous ICD: a review of the UNTOUCHED and PRAETORIAN trials. Arrhythm Electrophysiol Rev 10:108-112

13. Knops RE, Olde Nordkamp LRA, Delnoy PHM, Boersma LVA, Kuschyk J et al (2020) Subcutaneous or transvenous defibrillator therapy. N Engl J Med 383:526-536

14. Gold MR, Lambiase PD, El-Chami MF, Knops RE, Aasbo JD, Bongiorni MG et al (2021) Primary results from the understanding outcomes with the S-ICD in primary prevention patients with low ejection fraction (UNTOUCHED) trial. Circulation 143:7-17

15. Botto GL, Forleo GB, Capucci A, Solimene F, Vado A, Bertero $\mathrm{G}$ et al (2017) The Italian subcutaneous implantable cardioverterdefibrillator survey: S-ICD, why not? Europace 19:1826-1832

16. Tjong FVY. Koop BE. The modular cardiac rhythm management system: the EMPOWER leadless pacemaker and the EMBLEM subcutaneous ICD. Herzschr Elektrophys $2018 \cdot$ 29:355-361.

17. Mullens W, Auricchio A, Martens P, Witte K, Cowie MR, Delgado V et al (2020) Optimized implementation of cardiac resynchronization therapy: a call for action for referral and optimization of care. Eur J Heart Fail 22:2349-2369

18. Poole JE, Gold MR (2013) Who should receive the subcutaneous implanted defibrillator? The subcutaneous implantable cardioverter defibrillator (ICD) should be considered in all ICD patients who do not require pacing. Circ Arrhythm Electrophysiol 6:1236-1244

19. Maria ED, Olaru A, Cappelli S (2015) The entirely subcutaneous defibrillator (S-Icd): state of the art and selection of the ideal candidate. Curr Cardiol Rev 11:180-186

20. Forleo GB, Gasperetti A, Breitenstein A, Laredo M, Schiavone M, Ziacchi M et al (2021) Subcutaneous implantable cardioverterdefibrillator and defibrillation testing: a propensity-matched pilot study. Heart Rhythm 18:2072-2079 